\title{
Research the applicability of DOE about optimizing manufacturing process parameters
}

\author{
XinHu Zhang ${ }^{1, a}$, Min Huang ${ }^{2, b}$ \\ ${ }^{1}$ BeiHang University XueYuan Road NO.37, HaiDian District, Beijing, China; \\ ${ }^{2}$ BeiHang University XueYuan Road NO.37, HaiDian District, Beijing, China. \\ abuaazhangxinhu@foxmail.com, bbuaahuang@163.com
}

\begin{abstract}
Keywords: Process Parameter, DOE, Orthogonal Design, Uniform Design, Robust Parameter Design, Flame Spraying, Casting Process.
\end{abstract}

\begin{abstract}
The reliability of process system not only affects the production and qualified rate of the product, due to the imperfect system of process causing the defects in the manufacturing process, but also makes the product producing early fault or reducing the service life. Therefore, the reliability of process system has a great influence on the reliability, availability and maintenance cost of the product. The influence of process parameters on the reliability of process system is very great. If we can optimize the process parameters, it must improve the reliability of process system. As a result, the process system also must produce the high quality products. The design of experiment (DOE) is a good method to optimize the process parameters, and it is divided into the real test and the computer simulation experiment in this paper. The methods of experiment are applied to solving the problem about real test and simulation test. This paper uses the design of uniform experiment to solving the problem about casting process simulation of turbine stator blade, and uses the design of robust parameter experiment to solving the problem about flame spraying process of compressor casing.
\end{abstract}

\section{Introduction}

In order to solve the problem of the optimization of process parameters, this paper introduces the design of experiment to the process system. The paper studies the applicability of the orthogonal test design, the Latin hypercube design, robust parameter design, regression orthogonal rotation design and evolutionary operation experiment design in the system of process, which has a complete set of methodology to solving the problem of process parameters optimization. The paper also puts forward the applicable conditions of the experimental methods in the process of the real test and the computer simulation experiment. The methods of experiment make the optimization of process parameters more accurate, thus improve the reliability of process system [1].

\section{The applicability of DOE in the process system}

We know that there are so many methods of experiment, such as orthogonal design, uniform design, mixture design, robust parameter design, and so on. Those methods of experiment are referenced to different fields, but each method has limitation that makes no single method can solve all the problems. So it is necessary to select a different experiment design to solve different problem [2].

\section{Dividing the methods of experiment}

According to researching the methods of experiment and process system, this paper summarizes five methods for solving the problem of process parameter optimization. They are divided into two categories based on real test and simulation test according to the pros and cons of methods. At the same time, this paper summarizes the application of each method [3].

The classification of test methods is as followed Fig.1. 


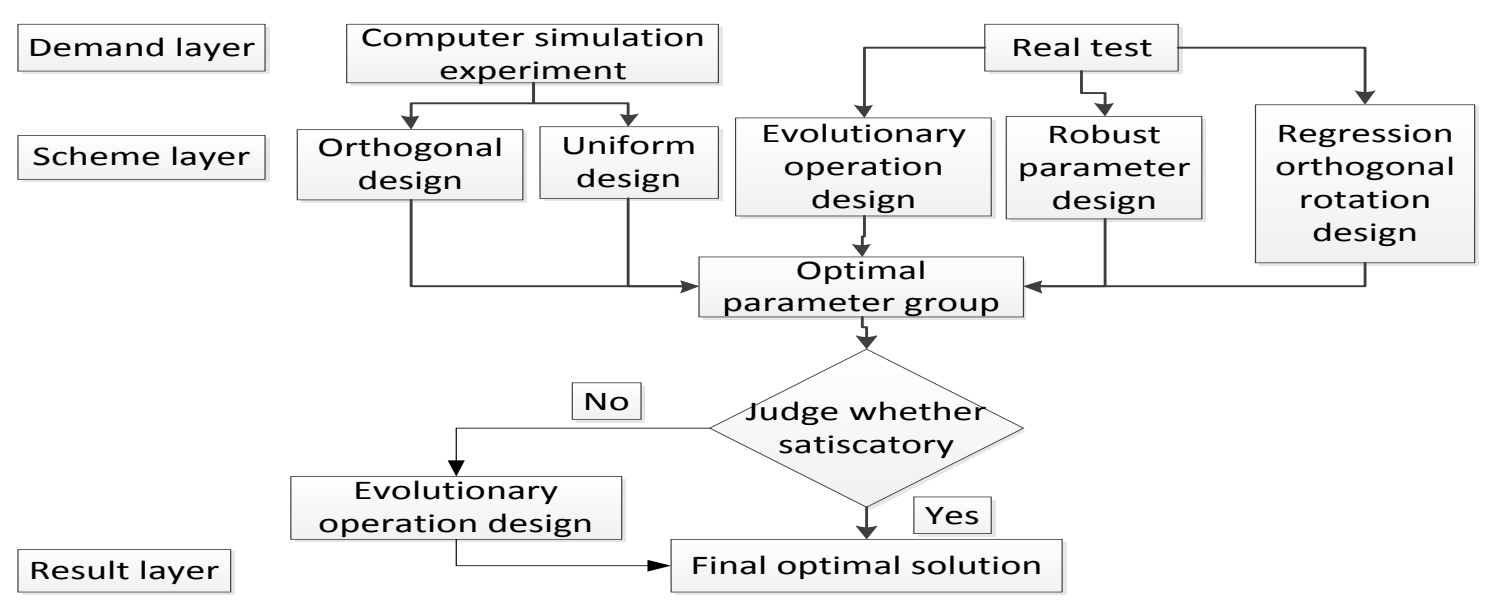

Fig. 1 the classification of experiment

\section{The basis of dividing the methods of experiment}

According to random error and system error, this paper divides the above five methods of experiment into real test and simulation test [4].

(1) Under certain experimental conditions, random error is the error with unpredictable changes that absolute error not only is positive but also is negative. Random error generally has statistical law that is mostly normal distribution. Therefore, the mean of many tests' random error is smaller than the random error of individual trials, which make the random error reduced by increasing the number of tests.

(2) Under certain experimental conditions, system error is the error that is affected by one or some factors acting in accordance with a defined law. The value and symbol of system error is constant in the same test, and system error is changed in accordance with a defined law in some conditions. When the condition of experiment is established, the system error is a constant objective, which can't be discovered by the number of trial, nor be reduced by the mean of trials [5].

(3) Computer simulation experiment that its error comes from system error has certainty, which generally don't consider random error. The test point doesn't need to repeat, but the point of test try to fill the design space.

(4) Orthogonal design and uniform design's space filling and equilibrium are very excellent, so as that they have priority in computer simulation experiment.

(5) Real test has more random error. In order to eliminate random error, the points should be repeated, which can reduce the random error.

(6) Robust parameter design not only considers the test factors, but also considers the error factors. Therefore, it is suitable to the real test. Regression orthogonal rotation design can reduce the random error through repeating the test point during real test.

(7) Evolutionary operation experiment design is devoted to the real test. It is a simple and easy test that production and process improvement are simultaneously.

\section{The applicability of real test}

Although robust parameter design and regression orthogonal rotation design can be applied to real test, they have some differences. Evolutionary operation experiment design is devoted to the real test.

(1) Robust parameter design considers the noise factor, while regression orthogonal rotation design reduces the random error by repeating the test points.

(2) When dealing with data of experiment, regression orthogonal rotation design can develop a linear relationship between the factor and the indicator. Robust parameter design assesses the impact about factor and indicator by SN ratio. 


\section{The applicability of computer simulation experiment}

Orthogonal design and uniform design can be used in computer simulation experiment, while their respective disadvantage and advantage determine their scope of using [6].

(1) Orthogonal design has more stringent level of factor than uniform design, and uniform design can take more levels of factor. Especially the level of factor is consequent, uniform design is better than orthogonal design.

(2) Orthogonal design considers the interaction between factors, while uniform design does not consider the interaction.

(3) The number of orthogonal design tests increases with exponentially. The number of trials of uniform design is exactly equal to the number of level of factor. Therefore it greatly reduced the number of trials. When the number of level is more, uniform design is preferred.

\section{Application of experiment}

\section{Casting process simulation experiment about turbine stator blades}

The case is the application of uniform, and the test subject is casting process simulation experiment about turbine stator blades. PROCAST is the simulation software. The experiment will find out the optimal process parameter and solve the problem of the shrinkage of turbine stator casting process.

Table 1 the factors and range

\begin{tabular}{ccccc}
\hline factor & $\begin{array}{c}\text { temperature of } \\
\text { molten metal }\end{array}$ & $\begin{array}{c}\text { temperature of } \\
\text { mold shell }\end{array}$ & $\begin{array}{c}\text { thickness of } \\
\text { mold shell }\end{array}$ & holding time \\
\hline level & $1400-1500^{\circ} \mathrm{C}$ & $1100-1200^{\circ} \mathrm{C}$ & $6-10 \mathrm{~mm}$ & $1-3 \mathrm{~min}$ \\
\hline
\end{tabular}

Table 2 the scheme of casting process simulation

\begin{tabular}{cccccc}
\hline $\begin{array}{c}\text { factor } \\
\text { number }\end{array}$ & $\begin{array}{c}\text { temperature of } \\
\text { molten metal }\end{array}$ & $\begin{array}{c}\text { temperature of } \\
\text { mold shell }\end{array}$ & $\begin{array}{c}\text { thickness of } \\
\text { mold shell }\end{array}$ & $\begin{array}{c}\text { holding } \\
\text { time }\end{array}$ & $\begin{array}{c}\text { shrinkage } \\
\text { volume }\end{array}$ \\
\hline 1 & 1438 & 1157 & 8.7 & 2.2 & 1.76 \\
2 & 1432 & 1152 & 8.9 & 1.9 & 2.54 \\
3 & 1486 & 1107 & 7.5 & 2.9 & 8.11 \\
4 & 1491 & 1197 & 8.1 & 2.8 & 6.44 \\
5 & 1413 & 1187 & 9.1 & 1.2 & 5.70 \\
6 & 1448 & 1167 & 7.3 & 2.3 & 2.08 \\
7 & 1442 & 1164 & 8.6 & 2.1 & 1.95 \\
8 & 1463 & 1183 & 9.5 & 1.7 & 4.29 \\
9 & 1478 & 1123 & 9.9 & 1.5 & 6.22 \\
10 & 1483 & 1192 & 6.2 & 2.7 & 5.97 \\
11 & 1423 & 1144 & 6.3 & 2.3 & 3.33 \\
12 & 1472 & 1132 & 7.9 & 1.1 & 5.33 \\
13 & 1468 & 1177 & 9.3 & 1.6 & 4.91 \\
14 & 1408 & 1117 & 6.7 & 1.3 & 7.12 \\
15 & 1403 & 1114 & 8.3 & 1.4 & 8.75 \\
16 & 1453 & 1149 & 6.5 & 2.0 & 2.98 \\
17 & 1497 & 1103 & 9.7 & 2.9 & 9.39 \\
18 & 1429 & 1174 & 6.9 & 1.7 & 3.61 \\
19 & 1456 & 1138 & 7.2 & 2.5 & 3.91 \\
20 & 1418 & 1128 & 7.8 & 2.5 & 4.56 \\
\hline
\end{tabular}

According to the scheme of trial, carry out experiment and record the indicator values. The results of experiment were analyzed as follows Fig. 2. 
We can find out that the temperature of molten metal, temperature of mold shell and holding time has great impact on shrinkage volume. We can get the optimal parameter combination by fitting experimental points.
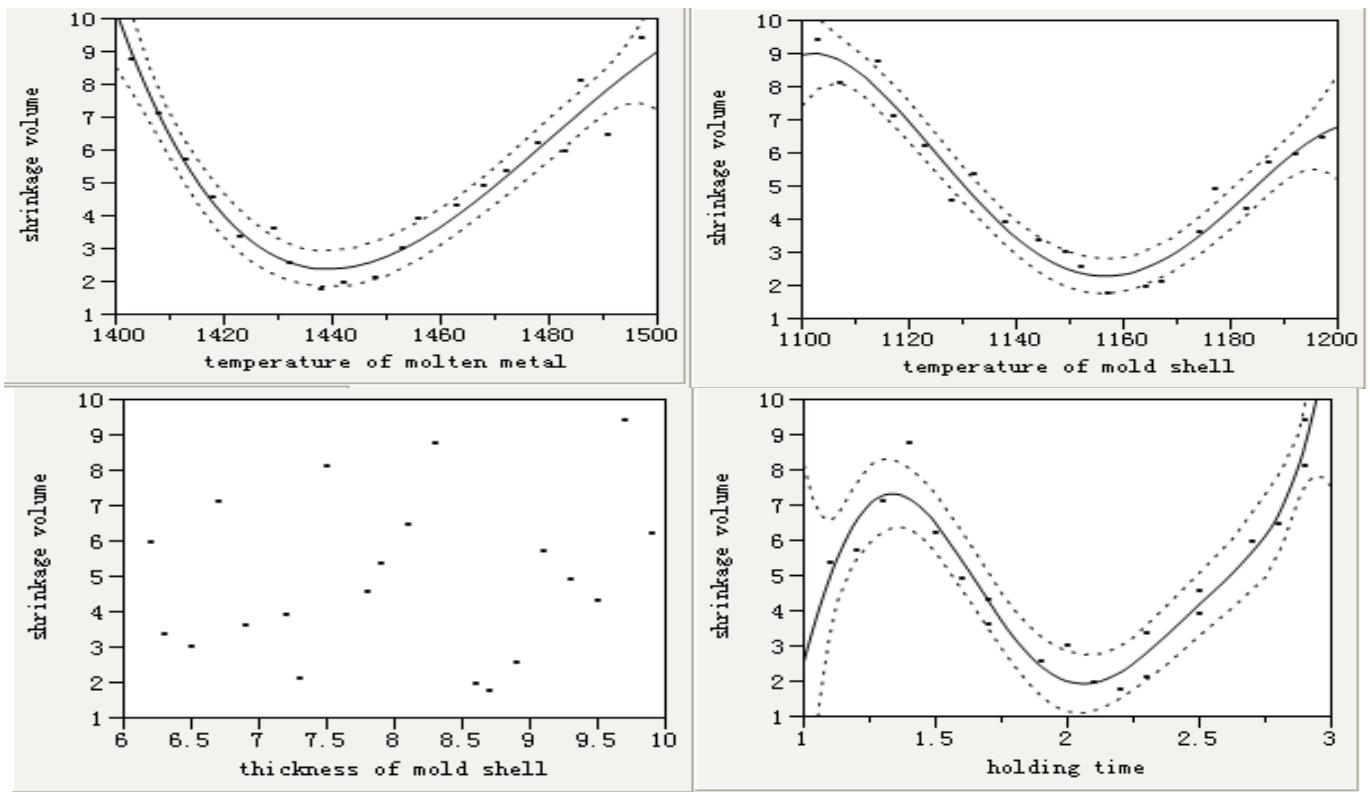

Fig.2 the results of experiment analysis

\section{The experiment of flame spraying process of compressor}

The case is the application of robust parameter design, and the test subject is the flame spraying process of compressor. By analyzing the impact between the factors and the indicators, it can find out the optimal process parameters to improve the reliability of flame spraying process.

The factor and the indicator are as followed:

Control factor: oxygen pressure (28-36) psi, acetylene pressure (14-22) psi, nitrogen pressure (50 - 58) psi, oxygen flow (90-96) SCFH, acetylene flow (48-54) SCFH, nitrogen flow (12-14) SCFH, the amount of powder feeding (70-90) \%RPM.

Error factor: spray distance (210-230) mm.

Signal factor: nickel graphite additive (3-6) \%.

The test indicator: bond strength $(\mathrm{MPa})>=5 \mathrm{Mpa}$, porosity $=<25 \%$.

The experiment makes use of direct product design and inside and outside table. The scheme of robust parameter design is as followed:

Table 3 the scheme of flame spraying

\begin{tabular}{|c|c|c|c|c|c|c|c|c|c|c|c|c|}
\hline \multicolumn{8}{|c|}{$\begin{array}{l}\text { The scheme of robust parameter design of flame } \\
\text { spraying process of compressor }\end{array}$} & \multirow{2}{*}{$\begin{array}{c}\begin{array}{c}\text { number } \\
\text { factor }\end{array} \\
\mathrm{H}\end{array}$} & \multirow{2}{*}{$\begin{array}{c}1 \\
210\end{array}$} & \multirow{2}{*}{$\begin{array}{c}2 \\
210\end{array}$} & \multirow{2}{*}{$\begin{array}{c}3 \\
230\end{array}$} & \multirow{2}{*}{$\begin{array}{c}4 \\
230\end{array}$} \\
\hline & & & & & & & & & & & & \\
\hline $\begin{array}{l}\text { factor } \\
\text { number }\end{array}$ & A & B & C & $\mathrm{D}$ & E & $\mathrm{F}$ & $\mathrm{G}$ & L & 3 & 6 & 3 & 6 \\
\hline 1 & 28 & 14 & 50 & 90 & 48 & 12 & 70 & & & & & \\
\hline 2 & 28 & 14 & 50 & 90 & 51 & 13 & 80 & & & & & \\
\hline 3 & 28 & 14 & 50 & 90 & 54 & 14 & 90 & & & & & \\
\hline 4 & 28 & 18 & 54 & 93 & 48 & 12 & 70 & & & & & \\
\hline 5 & 28 & 18 & 54 & 93 & 51 & 13 & 80 & & & & & \\
\hline 6 & 28 & 18 & 54 & 93 & 54 & 14 & 90 & & & & & \\
\hline 7 & 28 & 22 & 58 & 96 & 48 & 12 & 70 & & & & & \\
\hline 8 & 28 & 22 & 58 & 96 & 51 & 13 & 80 & & & & & \\
\hline 9 & 28 & 22 & 58 & 96 & 54 & 14 & 90 & & & & & \\
\hline 10 & 32 & 14 & 54 & 96 & 48 & 13 & 90 & & & & & \\
\hline
\end{tabular}




\begin{tabular}{llllllll}
\hline 11 & 32 & 14 & 54 & 96 & 51 & 14 & 70 \\
12 & 32 & 14 & 54 & 96 & 54 & 12 & 80 \\
13 & 32 & 18 & 58 & 90 & 48 & 13 & 90 \\
14 & 32 & 18 & 58 & 90 & 51 & 14 & 70 \\
15 & 32 & 18 & 58 & 90 & 54 & 12 & 80 \\
16 & 32 & 22 & 50 & 93 & 48 & 13 & 90 \\
17 & 32 & 22 & 50 & 93 & 51 & 14 & 70 \\
18 & 32 & 22 & 50 & 93 & 54 & 12 & 80 \\
19 & 36 & 14 & 58 & 93 & 48 & 14 & 80 \\
20 & 36 & 14 & 58 & 93 & 51 & 12 & 90 \\
21 & 36 & 14 & 58 & 93 & 54 & 13 & 70 \\
22 & 36 & 18 & 50 & 96 & 48 & 14 & 80 \\
23 & 36 & 18 & 50 & 96 & 51 & 12 & 90 \\
24 & 36 & 18 & 50 & 96 & 54 & 13 & 70 \\
25 & 36 & 22 & 54 & 90 & 48 & 14 & 80 \\
26 & 36 & 22 & 54 & 90 & 51 & 12 & 90 \\
27 & 36 & 22 & 54 & 90 & 54 & 13 & 70 \\
\hline
\end{tabular}

According to the scheme of trial, carry out experiment and record the indicator values.

The visual analysis and variance analysis of bond strength as follows Fig. 3 and Table 4. The visual analysis and variance analysis of porosity as follows Fig. 4 and Table 5

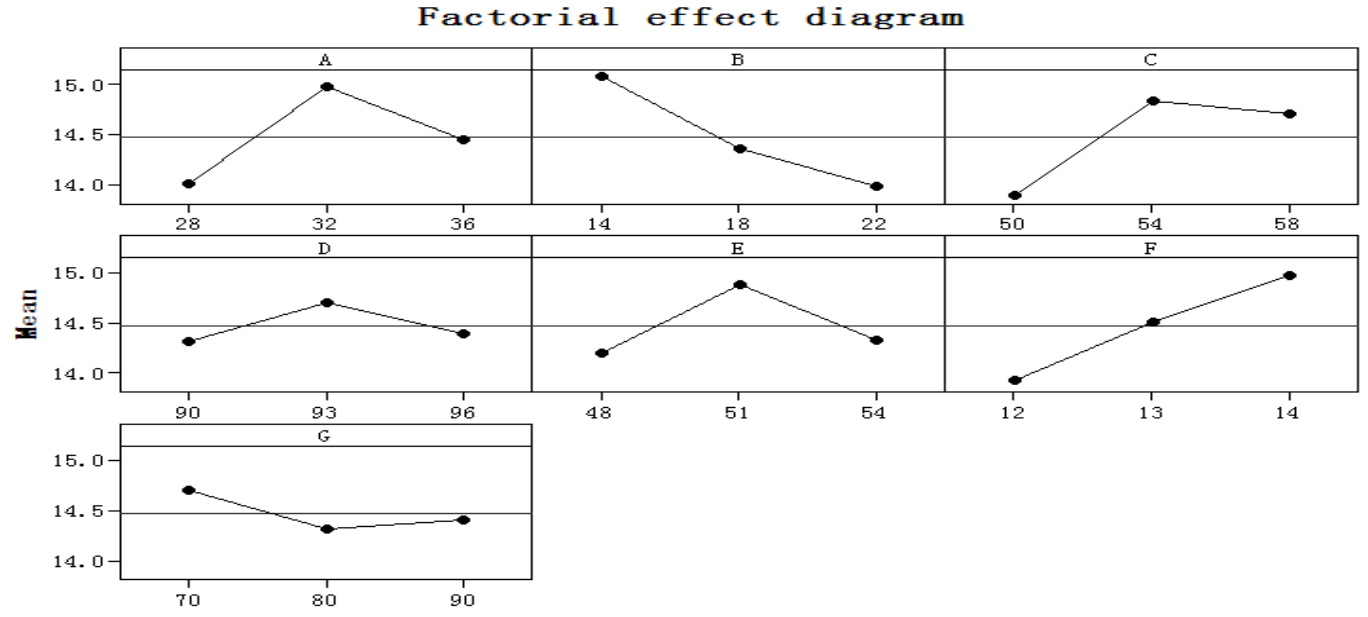

Fig. 3 the visual analysis of bond strength

Table 4 the variance analysis of bond strength

\begin{tabular}{cccccc}
\hline Origin & Freedom & SS & MS & F & P \\
\hline A & 2 & 4.2394 & 2.1197 & 8.51 & 0.005 \\
B & 2 & 5.5279 & 2.7640 & 11.09 & 0.002 \\
C & 2 & 4.7468 & 2.3734 & 9.53 & 0.003 \\
D & 2 & 0.7626 & 0.3813 & 1.53 & 0.256 \\
E & 2 & 2.3470 & 1.1735 & 4.71 & 0.031 \\
F & 2 & 5.0231 & 2.5115 & 10.08 & 0.003 \\
G & 2 & 0.7449 & 0.3725 & 1.50 & 0.263 \\
Error & 12 & 2.9896 & 0.2491 & & \\
Total & 26 & 26.3814 & & & \\
\hline
\end{tabular}




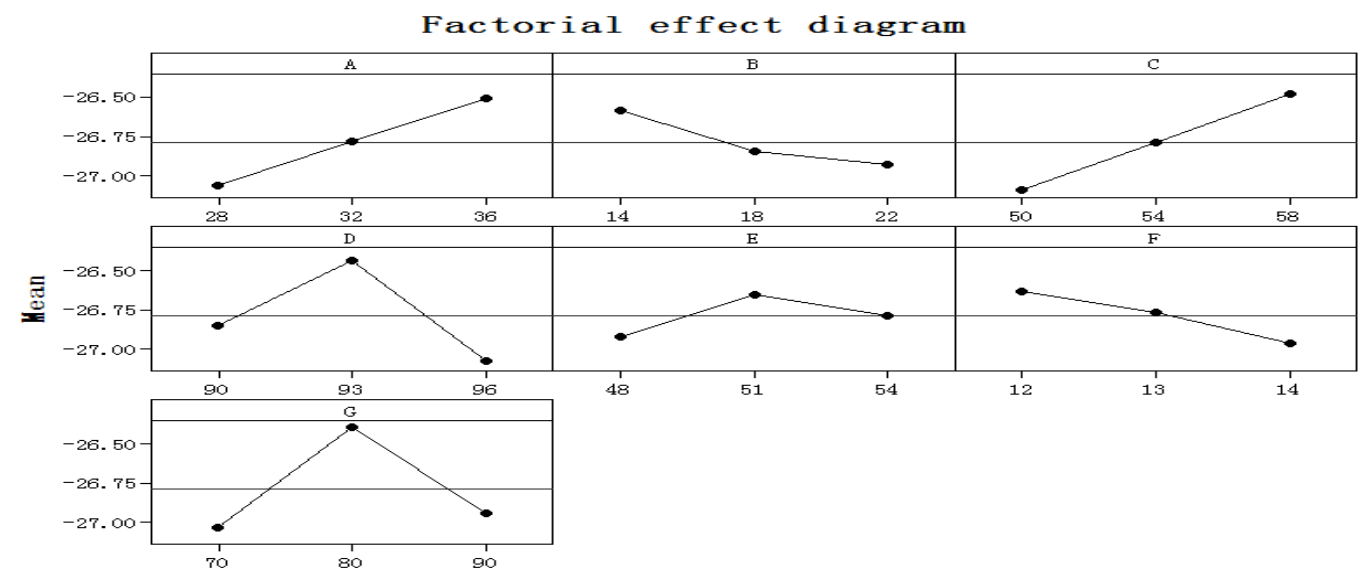

Fig. 4 the visual analysis of porosity

Table 5 the variance analysis of porosity

\begin{tabular}{cccccc}
\hline Origin & Freedom & SS & MS & F & P \\
\hline A & 2 & 1.37739 & 0.68869 & 9.33 & 0.004 \\
B & 2 & 0.57949 & 0.28975 & 3.93 & 0.049 \\
C & 2 & 1.67201 & 0.83601 & 11.33 & 0.002 \\
D & 2 & 1.93826 & 0.96913 & 13.13 & 0.001 \\
E & 2 & 0.31567 & 0.15783 & 2.14 & 0.161 \\
F & 2 & 0.50382 & 0.25191 & 3.41 & 0.067 \\
G & 2 & 2.14303 & 1.07152 & 14.52 & 0.001 \\
Error & 12 & 0.88583 & 0.07382 & & \\
Total & 26 & 9.41549 & & & \\
\hline
\end{tabular}

We can find out the optimal parameter combination from the figures and tables above.

\section{Summary}

In this paper, the applicability of the design of experiment was studied on optimizing the process parameters. The methods of real and simulation test are applied to casting process and flame spraying. The problems of turbine stator blade casting process parameters and compressor mechanical flame spraying process parameters were resolved by uniform design and robust parameter design.

\section{References}

[1] McKay M.D, Beckman R.J, Conover W.J, A Comparison of Three Methods for Selecting Values of Input Variables in the Analysis of Output from a Computer Code, J. Technometrics. 21(1979)239-245.

[2] Morris M.D, Mitchell T.J, Exploratory Designs for Computational Experiments, J. Journal of Statistical Planning and Inference. 43(1995)381-402.

[3] Montgomery D.C, Design and Analysis of Experiment (Second Edition), New York, 1984.

[4] Ren L.Q, Experiment study on bionic non-smooth surface soil eletro-osmosis, J. International Agricultural Engineering Journal. 83(1999)185-196.

[5] D.R. Cox, N.Reidd, The theory of the Design of Experiments, Chapman \& Hall/CRC, 2000.

[6] Burgess. L, Optimal Designs for choice experiments with asymmetric attributes, J. Journal of Statistical Planning and Inference. 134(2005)288-301. 